\title{
Public Libraries and Higher Education Combining Efforts to Create Quality STEM Children's Programs
}

\author{
Tracey. A. Overbey, The Ohio State University Libraries \\ Daniel S. Dotson, The Ohio State University Libraries \\ Molly Meyers Labadie, Worthington Libraries
}

\begin{abstract}
Science, Technology, Engineering, and Mathematics (STEM) fields are a major component of our society and student success in STEM can lead to important opportunities and future careers. STEM education programs are important components to get children and youths interested in STEM fields and to instill in them STEM concepts. This paper describes two successful Ohio urban STEM programs, produced as collaborations between public libraries and higher education institutions. Cleveland's Mean Green Science Machine focused on middle and high school-aged children while The Ohio State University (OSU) Science Café in Columbus focused on preschool and elementary school-aged children for its summer sessions. Recommendations for best practices for creating children’s programming using STEM is provided.
\end{abstract}

\section{Introduction}

Science, technology, engineering, and mathematics (STEM) education is covered in many scholarly publications, government studies and reports, and news stories as a key component to the future success of the United States and its citizens. STEM education is necessary for future success of students, where many careers depend upon STEM knowledge and often degrees from higher education institutions. 
Ohio is ranked as the seventh most populous U.S. state (United States Census Bureau 2017). In terms of business, it ranks fifth in the country for being home to Fortune 500 companies, with 23 of these companies. These companies include areas such as retail (Kroger, Macy’s, etc.), healthcare (Cardinal Health, Omnicare, etc.), energy (Marathon Petroleum, American Electric Power, etc.), finance and insurance (Nationwide, Fifth Third Bancorp, etc.), the chemical industry (Proctor \& Gamble, Sherwin-Williams, etc.), and other industries (Dempsey 2015). All of these large companies depend, on varying degrees, on STEM fields for their success. Graduates in areas such as agriculture, chemistry, computer science, earth sciences, engineering, food sciences, mathematics/statistics, pharmacy, and other areas can contribute to the success of these companies. Combining its large population and the important businesses headquartered in Ohio, STEM education is important to the future of Ohio especially its current and future students.

In terms of educational institutions, Ohio is also home to:

- 37 public universities and community colleges serving nearly 600,000 students. Also, dozens of private non-profit, as well as for-profit, colleges and universities are present in Ohio (Department of Higher Education 2017).

- 251 public library systems with 481 branch locations (State Library of Ohio 2017).

- More than 600 public school districts serving K-12 students (Ohio Department of Education 2017). 
Thus, STEM education opportunities in Ohio are numerous and with all the institutions in the above figures, opportunities for collaboration among those institutions, in addition to the private sector, are also numerous.

While collaboration is common when libraries think of their collections and spaces, developing partnerships to produce programming is less common. Combine this with the importance of STEM education, public libraries and higher education institutions are in a position to collaborate to create quality STEM programming to increase interest in, exposure to, and learning opportunities to STEM fields and their experts.

This article illustrates two collaborative urban STEM programs developed in the state of Ohio that involve public libraries collaborating with universities in order to produce quality learning experiences for children. The Mean Green Science Machine is a collaboration between Cleveland Public Library and both Case Western Reserve University and The Ohio State University Extension and targets middle and high school students. The Ohio State University Science Café’s summer events are a collaboration between The Ohio State University and Worthington Libraries) targets primarily preschool and elementary school children.

\section{Literature Review}

The Value of STEM programs is well-documented within the literature. The National Science Board (2010) issued its Science and Engineering Indicators 2010 indicates there are multiple concerns when it comes to STEM education and children. The indications included: 
- Teachers who teach elementary-aged, and in many cases middle-school aged, children mathematics and science usually do not have degrees in those disciplines.

- Low-income or low-achieving students are less often taught science or mathematics skills in the eighth grade by teachers with an advanced or science/mathematics degree.

- The U.S. is outperformed on science/mathematics tests by several countries. Lowachievers, Black and Hispanic students tend to have lower scores on science/mathematics standardized tests.

The indicators also include some positive notes that encourage STEM education:

- Students who completed advanced science and mathematics courses in high school were more likely to attend college and less likely to need remediation there.

- In households with a Bachelor degree or higher, students were more likely to be taught advanced science and mathematics skills in the 8th grade or higher.

- More concentrations in the STEM areas are in high demand, with areas classified by science and engineering expected to increase at more than double the overall grown rate for all occupations.

Libraries are making great strides to incorporate STEM into programming, which leads researchers to recognize and study the impact of such programming. In a thesis by Jeffrey B. Harris (2015), he noted that there are libraries that are attempting to offer relevant programing using STEM. Libraries have realized the importance of promoting science literacy and supporting a deeper understanding for better preparedness for future generations. 
The College of William and Mary in Virginia collaborated on a summer program for specific STEM and other interests with gifted youth, taught by college faculty and area teachers (Peterson 1992). Another project at Harvard involved a network of ecological research sites that paired scientists with teachers in order to give their students (5th grade) a "citizen science” experience with scientific research (Bennett 2010). STEM programs for children are not just a phenomenon found in the United States. As part of 'The Blue Marble' project, Scientists at the Universities of Leicester and Nottingham (United Kingdom) developed day-long, interdisciplinary, hands-on workshops for primary schools to introduce space technology and the role of the research scientist (Muller 2013).

STEM programs, including using story hour, can be used to generate interest in STEM fields. The best time to begin implementing STEM programs is when children are young, starting around age four, when children can begin to grasp basic concepts. Early exposure to STEM can develop interests that lead to opportunities later in life. Local companies may even be willing to provide financial assistance for STEM programs (Reighard, Torres-Crespo and Vogel 2016).

Public funding is often lower in areas with a large population of color. Vocation education, such as mechanics or carpentry, is no longer a commonplace in schools. This translates to less exposure to STEM disciplines. Libraries can help address this gap and help to provide STEM programming to the community. Proving education opportunities can eventually translate to improvements in the community as a better-educated populace tends to reduce delinquency, crime, and poverty (Roberson 2015). 
Examining people in the U.S. employed as scientists and engineers, the Black/African American and the Hispanic/Latino populations are underrepresented in these fields compared to their portion of the general population, as shown in Table 1 (National Science Foundation 2017). Studies have also shown that once minorities are exposed to the sciences, they tend to pursue the S\&E fields of study when entering college at the same rate as Whites and Asians (National Academy of Sciences, National Academy of Engineering, and Institute of Medicine 2011).

\section{[Insert Table 1]}

Working with a lower-income population does have some challenges beyond money. Lack of exposure to STEM may mean the population is less often familiar with the topics that a program could possibly cover. Unfamiliarity with topics such as computer gaming or gardening means those wishing to implement STEM programs need to do some investigation into the dynamics and interests of the local population. Then, scientists can be approached for their involvement. These scientists can be found at local universities or businesses that involve STEM fields, such as chemical plants (Roberson 2015).

Studies have shown STEM occupations result in higher than median wages when compared to workers who are not employed in STEM-related employment. Exposing children who visit the public libraries to the world of STEM can provide hope and employable ideas for the youth within those underrepresented communities. Sharing with students that their lives entail science daily, can stir enthusiasm for them to want to learn more about STEM. Relating these daily 
science involvements to them personally can stir excitement that would likely keep them participating in your science-based program (Sharma 2016).

Budgets are often quite limited for entities providing public services. Limited budgets point to the value of collaboration with other sectors or organizations to create STEM programming. To make it simple and less time consuming on ideas, community leaders, or stakeholders, it is valuable to narrow down program options based on the interests of its users. Taking these interests to the next level can expose young people to the ever-growing world that they enjoy participating in. Allowing openness to trying innovative ideas is a start. Getting the young people involved with the idea can also be supportive. Having a connection with the community and the youth can help in building your base for a hands-on learning STEM experience (Hopwood 2012).

Librarians without a STEM background who might feel intimidated about organizing a STEM program have options for help. For example, the National Center for Interactive Learning is working with the American Library Association to bring science to underrepresented populations throughout cities, where they educate public libraries on how to accomplish STEM-focused programming. Institutions committed to providing additional STEM-based programs following their first successful one, may want to use the Science Technology Activities and Resources. The "Star Library Education Network" is an online support network for public librarians to gain new ideas and insights from others involved in current and innovative programming. The Lunar and Planetary Institute also supports librarians wishing to start a STEM program (Dusenbery and LaConte 2016). 
Partnerships are valuable ways for libraries to create quality STEM programming, enabling them to do in collaboration what they might not be able to do on their own. Public libraries are changing. They provide many services to users today, including employment support, reader's advisory, and a wide range of programming, including those for its younger users. In order to remain relevant, it is important for librarians to form partnerships, to come out from behind our daily walls and explore with others to create (Dow 2014). Libraries create successful partnerships with schools, businesses, museums, recreation centers, food pantries and really anyone who can help positively impact and add value to our communities. Library collaborations have many benefits from access to a customer base, visibility for services/activities, gaining new skills, gains in expertise, and also energizing staff with new activities (Todaro 2005/6).

While academic and public libraries often collaborate when it comes to collections issues, programming collaborations are another possible area to combine resources. Academic and public library collaborations can lead to successful events. For example, an example of a nonSTEM collaboration between these two different library types involved a collaboration to put on a two-day event related to comics and anime led to increased visibility for both institutions (Palm Harbor Library (PHL) in Palm Harbor, Florida and St. Petersburg College’s (SPC) Tarpon Springs campus Library) involved. The two libraries split hosting of the two-day event and surveyed visitors, finding that $85 \%$ of attendees were not SPC students and over half of the attendees were under 18 (Knipp et al 2015). In Australia, public and academic libraries are both seen as having a role in improving early-childhood services (Lucas 2013). 
Higher education institutions (including, but not limited to, libraries) and public libraries bring to the table key advantages when it comes to collaborating on STEM programming. They have both unique and overlapping missions, resources, and skills. Many universities have a mission to provide outreach services to their local communities. At the same time, public libraries value collaborations to help offer the best programs and services to their communities. Advantages in collaborating may include sharing experience and ideas, offering additional services and raising awareness of programs and services. Challenges could be resources needed to be invested, acceptance of what different partners bring to the table, and a willingness to take risks or even fail (Sarjeant-Jenkins and Walker 2014).

In addition to higher education partners, public libraries may also consider partnering with businesses in the STEM field. An example of such a successful collaboration is the Mamie Doud Eisenhower Public Library in Broomfield, Colorado. It partnered using a grant application with Sandoz Pharmaceuticals, Inc. to create the Sandoz Science and Education Center on its first floor. The goal was to provide science education materials to the center's users. The materials included traditional materials such as databases, audiovisual materials, print materials, software, and online sources. The grant request also included the need for scientific equipment to be placed in the center. Also included was the need for increased services such as increased story hours in order to provide opportunities for children and youths in the community. Additionally, the library saw the need for the involvement of scientists and put out a request for scientist volunteers from the community to be part of their Science Task Force. The original idea for the task force to be focused on the center's materials changed to focus it on programming. Thus, the 
priority was to provide hands-on programs for the community. Involvement by scientists goes beyond those from Sandoz Pharmaceuticals, Inc. In addition to task force involvement, other scientists from the community regularly volunteer their services to the programs (Segraves 2012).

Partnerships are thus opportunities to provide quality programming. Collaborating with others allows combining of funding, staffing, expertise, spaces, and other aspects needed to provide quality programs to users. Programs related to STEM fields, which require expertise not often found in public libraries, is especially benefited by partnerships with institutions or businesses with that expertise.

\section{Case Study 1: The Mean Green Science Machine}

The Collaborators:

- Cleveland Public Library

- Cleveland Metropolitan School District

- Case Western Reserve University

- The Ohio State University (OSU) Extension

The Mean Green Science Machine (MGSM) was a grassroots STEM program for urban youth at the Cleveland Public Library. MGSM was designed to introduce today's youth to STEM by demonstrating how it can be explored within their daily lives, and encourage them to enrich the communities in which they reside. In today's world with all the environmental risk factors, it is important for new scientists to emerge and evolve with new discoveries and explorations.

[Insert Figure 1] 
Teaching youth to enjoy STEM brings on collaborations and dialogues, about the world in which they live. Exposing youth to STEM through hands-on activities shows young people the art of problem solving and perseverance. It also helps them evaluate the process in which things grow and evolve too. The learning process also encourages youth to believe they can genuinely contribute to a more sustainable, eco-friendly world. This was the vision for bringing STEM to children in a public library environment.

To implement STEM programming, considerations include questions of who, what, and where to find resources that could accommodate hands-on experience. Once identified, the librarian and staff must also be able to relate to and communicate with today’s youth about STEM. MGSM reached directly out to academic departments on college campuses. In retrospect, an easier angle may have been for the public librarians to collaborate with academic librarians in order to reach the scientists on college campuses. Often, academic librarians can provide valuable input in brainstorming which departments can best meet the program's mission. Furthermore, they will most likely have contact information of those who are open to bringing STEM programming to children in public libraries. While MGSM focused on large research universities (i.e. Case Western Reserve University and The Ohio State University Extension) to provide the scientists, other libraries may want to consider two- and four-year institutions as potential sources of scientists.

As mentioned earlier, many colleges and universities, particularly public institutions, have a mission to reach out to the community outside of campus. Many scientists are enthusiastic to share their research and procedures. Thus, collaborating with public libraries to produce STEM programming, such as MGSM, is mutually beneficial to all parties. MGSM reached out to 
science and math teachers in the Cleveland Metropolitan School District to assist in identifying students who would have home support as well as the ability to commit to the program for the duration.

In order to make the library a learning lab for youth, there are a few things to keep in mind during the planning process:

[Insert Table 2]

As public library employees or academic scholars, one primary objective is to educate. Part of a vital education for children is STEM, hence the program's goal of exposing children to STEM. Since STEM expertise was lacking in the Cleveland Public Library, it was vital to collaborate with other institutions to share resources and reduce overall expenditures.

During the early phase of planning, the MGSM a pre-evaluation was distributed to students, asking their take on STEM fields. Most students did not like STEM and did poorly in their STEM classes. A majority of students were not exposed to any careers in STEM fields, except for some instances of a family member in the medical field. Students did not know much about STEM in their daily lives based on the pre-evaluation.

After the four months of MGSM STEM hands-on activities within the libraries, a post-evaluation was distributed, asking students for their take on STEM fields. This evaluation was distributed after learning how to grow a lettuce garden, making ricotta cheese (which was the exposure to microbiology - students where told after making of the cheese itself). The students encountered STEM professionals such as a chemist who was in drug enforcement, and an aerospace engineer. Students all shared how they loved science now, did not know these things they encountered 
were STEM-related topics, and some students said they think they were born to be scientists. In fact, students shared how easy and fun STEM topics could be.

\section{Case Study 2: The Ohio State University (OSU) Science Café}

The Collaborators:

- The Ohio State University

- Worthington Libraries

In 2008, The Ohio State University (OSU) started hosting its Science Café at the Columbus campus. It is a series of talks on scientific topics open to the public, although the audience is mostly students and faculty. The OSU Science Café is co-sponsored by OSU Libraries and the OSU chapter of the scientific society Sigma Xi. Topics vary widely and have previously include the physics of Dr. Who, cat behavior, the Ice Age in Ohio, procrastination, Lyme disease, chocolate, and climate change. Most of the presenters are OSU researchers, usually faculty and graduate students.

Since the OSU campus is less busy with students and faculty during the summer, it was decided to try to target the program to children. The program was tested for two years to attract children to cafés on campus with only limited success. The program coordinators wanted a much bigger crowd and thought children could benefit from the summer cafés. If the children would not come to us, could the program go to the children? 
In 2010, the thought was to partner with local public libraries, hoping to get an audience for the summer cafés as public libraries are experts on summer programming for children. When trying to get a partnership off the ground, program coordinators should keep in mind any personal or professional connections. In the case of Science Café, a graduate school friendship helped to make the initial contact and early planning work much easier. Personal contacts allow them to take risks because they already know you and your strengths. After discussing, it decided to have a try with one café at one of Worthington Libraries’ branches (Worthington being just north of campus). Had there not already been an existing friendship, several other public library systems in the county were other potential partners.

The relationship between the OSU Science Café and Worthington Libraries grew from there. The relationship started out with just a single event and have expanded to having a program at each of their three branches each summer. For the past five years, attendance has never dropped under 50 for the summer cafés (it rarely goes over 50 for the “adult” ones). The ones at Worthington Libraries are averaging around 100. The audience is primarily preschool/elementary aged children and their parents.

Generally, the summer Science Café tend to have a speaker whose presentation is about animals, a person whose presentation leans towards chemistry, and someone whose presentation leans more towards physics. They are interactive and include bringing props and even live animals to demonstrate scientific principles to children. Program activities range from blowing up ping pong balls, teaching people to rip phonebooks in half, interacting and touching snakes, and blowing up marshmallows - all in the name of science! 
The time from planning to implementation actually takes several months. Figure 2 is a timeline for the year of planning for the summer cafés:

\section{[Insert Figure 2]}

After several years of working together on the summer cafes, Worthington Libraries and OSU have learned what works, what does not work, and in the process have learned a few lessons. Based upon this experience, here is some advice for those wanting to try a similar partnership:

[Insert Table 3]

By combining resources and expertise with the Worthington Libraries, the OSU Science Café is able to reach a much larger audience of children than when they tried it on their own. Worthington Libraries not only benefits from the expertise of the OSU Science Café speakers but also from having a high-quality program that does not affect their Summer Reading Club budget. A mutually beneficial relationship has thus led to a successful program. The benefits of this partnership included, both entities finding a new way to meet their mission, a positive experience that brings patrons into the library and science programs, a better relationship between university and public librarians that will benefit both in the years to come.

\section{Best Practices: Creating Your Own STEM Programs}


There are a number of questions librarians wishing to conduct STEM programing may want to consider. The following questions and answers consolidate advice based upon the experience gained from the two STEM program collaborations.

Question: Where can I find scientists?

Answer: Consider colleges and universities at all levels (2-year, 4-year, research) and both private and public. Public colleges/universities often have outreach missions to their community. Research labs, government agencies, and businesses may be other sources.

Question: Where can I find funding?

Answer: In addition to finding funding within your own organization or via any partners you work with, you may also consider seeking grants or donations. Library societies, businesses, and government agencies (such as the Institute of Museum and Library Services), may be sources of grants. Local businesses may be willing to provide donations. You may find scientists who will work for free, especially if their institution or business has an outreach mission or if their institution is a full partner.

Question: Where should we hold these programs?

Answer: Consider the easiest method to attract attention for the programs and the logistics for attending. The more barriers, the lower the attendance. While public library locations are often ideal, more formal multi-session programs may require visiting locations such as labs and outdoor venues. Consider transportation assistance in such cases. 
Question: How do you choose your participants?

Answer: Informal programs can get participants through the advertising normally done for the targeted age group. Formal programs, especially multi-session ones, will require more a more structured method with specific criteria

Question: What type of interactions best hold the interest of the participants?

Answer: Live demonstrations, props (animals, plants, etc.), and/or hands-on activities, especially for younger children, are a must for keeping audience attention.

Question: Will it be messy?

Answer: Probably. Demonstrations and experiments require cleanup. Plants need dirt. Expect a mess and prepare for cleanup. Consider outdoor options for events likely to be very messy.

Question: Will it be loud?

Answer: Probably. Explosions (a child favorite when it comes to science) make noise, as do animals. Also, do not expect children to sit quietly when such programs are occurring.

Question: How does feedback get gathered?

Answer: For formal programs, use formal evaluations to assess. If partnering, involve collaborators in creating the evaluation. For informal events, audience reactions can be observed. In both cases, regular consultations between collaborators before, during, and after the program/events should occur to exchange feedback from all parties. 
Question: How should success be determined?

Answer: For more informal events, audience count is one obvious criteria. One may also notice repeat visitors (within the same year and in repeated years). Requests for continue collaboration in subsequent years, and sometimes even requests for repeat of speakers, speak to success. For formal programs, analyzing evaluations to determine achievement in specified criteria is a likely occurrence.

\section{Conclusions}

STEM programs are a valuable way to increase knowledge in and exposure to STEM topics and researchers. With STEM occupations being sought by employers, education in STEM disciplines is an important venture for librarians to consider. Collaborations are often necessary to put on STEM programming, with colleges/universities, research lab, and businesses needed to provide access to the scientists who will need to be the presenters at library-provided STEM programs.

The two case study programs discussed illustrate the possibility of libraries working with colleges and universities to create quality STEM programming for children. In one case, MGSM, the public library reached out to universities while in the other program, OSU Science Café, the university reached out to the public library. Public libraries have children. Colleges and universities have scientists. By libraries working together, STEM programming can be created to bring quality experiences to children. 


\section{References}

Bennett, Katherine. 2010. Citizen Scientists. Science and Children 48 (1): 50-53. http://static.nsta.org/files/sc1009_50.pdf.

Dempsey, Caitlin. 2015. Fortune 500 List by State for 2015. Accessed July 30, 2017. https://www.geolounge.com/fortune-500-list-by-state-for-2015/.

Department of Higher Education. 2017. Ohio’s Campuses. Accessed July 30, 2017. https://www.ohiohighered.org/campuses.

Dow, Mirah J. 2014. Creating a STEM-Literate Society. Knowledge Quest 42 (5): 14-18. http://www.ala.org/aasl/pubs/kq/v42no5.

Dusenbery, Paul and Keliann LaConte. 2016. Interview by Young Adult Library Services. Public Libraries and STEM. Young Adult Library Services 14 (2): 10-13. http://yalsdigital.ala.org/i/628356-vol-14-no-2-winter-2016/11.

Harris, Jeffrey B. STEM Implementation in the School Library. Master's thesis, University of Central Missouri, 2015. http://centralspace.ucmo.edu/handle/123456789/420. 
Hopwood, Jennifer. 2012. Initiating STEM Learning in Libraries. Children \& Libraries: The Journal of the Association for Library Service to Children 10 (2): 53-55.

http://journals.ala.org/cal/article/download/43/18\#page=54.

Knipp, Paula J., Karen R. Walker, Kiki Durney, and Jorge E. Perez. 2015. Public and academic library collaboration through an anime and comics enthusiasts convention (ACEcon), Journal of Library Innovation 6 (2): 73-88. http://www.libraryinnovation.org/article/download/393/684.

Lucas, Freya. 2013. Many Spokes, Same Hub: Facilitating Collaboration Among Library and Early-Childhood Services to Improve Outcomes for Children. The Australian Library Journal 62 (3): 196-203. http://dx.doi.org/10.1080/00049670.2013.815576.

Muller, Catherine L., et al. 2013. The Blue Marble: A Model for Primary School STEM Outreach. Physics Education 48 (2): 176-183. http://dx.doi.org/10.1088/0031-9120/48/2/176.

National Academy of Sciences, National Academy of Engineering, and Institute of Medicine. 2011. Expanding Underrepresented Minority Participation: America's Science and Technology Talent at the Crossroads. Washington, DC: The National Academies Press. https://doi.org/10.17226/12984.

National Science Board. 2010. Science and Engineering Indicators 2010. Accessed July 30, 2017. http://files.eric.ed.gov/fulltext/ED514060.pdf. 
National Science Foundation. 2017. Women, Minorities, and Persons with Disabilities in Science and Engineering: Data Tables. Accessed August 4, 2017. https://www.nsf.gov/statistics/2017/nsf17310/data.cfm.

Ohio Department of Education. 2017. OEDS Reports. Accessed July 30, 2017. https://oeds.ode.state.oh.us/DataExtract.

Peterson, Kristina, Joyce VanTassel-Baska, and Jane M. Bailey. 1992. Summer Programs for Gifted Learners at The College Of William and Mary. Gifted Child Today Magazine 15 (4): 2-8. https://doi.org/10.1177/107621759201500401.

Reighard, Carly, Marisel Torres-Crespo, and Janet Vogel. 2016. STEM Curiosity Academy. Children \& Libraries: The Journal of the Association for Library Service to Children 14 (4): 32-35. http://dx.doi.org/10.5860/cal.14n4.32.

Roberson, Tezeno L. 1. 2015. “STEM”-Ulating Young Minds: Creating Science-Based Programming @ Your Library. Journal of Library Administration 55 (3): 192-201. http://dx.doi.org/10.1080/01930826.2015.1034041.

Sarjeant-Jenkins, Rachel and Keith Walker. 2014. Library Partnerships and Organizational Culture: A Case Study. Journal of Library Administration 54 (6): 445-461. http://dx.doi.org/10.1080/01930826.2014.953384. 
Segraves, Erica. 2012. A New Evolution in Science Collaboration. In Partnerships and collaborations in public library communities: Resources and solutions, ed. Karen Ellis, 66-78. Hershey, PA: Information Science Reference.

Sharma, Dilnavaz Mirza. 2016. Does STEM Education Belong in the Public Library? Public Libraries 55 (2): 17-19.

State Library of Ohio. Find an Ohio Library. 2017. Accessed July 30, 2017. https://library.ohio.gov/using-the-library/find-an-ohio-library/\#PublicLibraries.

Todaro, Julie Beth. 2005/2006. Community Collaborations at Work and in Practice Today: An A to Z overview. Resource Sharing \& Information Networks 18 (1-2): 137-156. http://dx.doi.org/10.1300/J121v18n01_11.

United States Census Bureau. 2017. U.S. and World Population Clock. Accessed August 4, 2017. https://www.census.gov/popclock/. 